\title{
The experiences and needs of people seeking palliative health care out-of-hours: a qualitative study
}

\author{
Suzanne H. Richards ${ }^{1}$, Rachel Winder ${ }^{2}$, Clare Seamark $^{3}$, David Seamark ${ }^{3,4}$, Sarah Avery $^{5}$, James Gilbert $^{6}$, \\ Angela Barwick ${ }^{7}$ and John L. Campbell ${ }^{8}$ \\ ${ }^{1}$ Senior Lecturer in Primary Care, Department of Primary Care, Peninsula College of Medicine and Dentistry, \\ St Luke's Campus, University of Exeter, Exeter, UK \\ ${ }^{2}$ Research Fellow, Department of Primary Care, Peninsula College of Medicine and Dentistry, St Luke's Campus, \\ University of Exeter, Exeter, UK \\ ${ }^{3}$ General Practitioner, Honiton Surgery, Marlpits Lane, Honiton, UK \\ ${ }^{4}$ Honorary Senior Clinical Research Fellow and General Practitioner, Department of Primary Care, Peninsula College \\ of Medicine and Dentistry, St Luke's Campus, University of Exeter, Exeter, UK \\ ${ }^{5}$ Clinical Governance Manager, Devon Doctors, Unit 10 Manaton Court, Manaton Close, Matford Business Park, \\ Exeter, UK \\ ${ }^{6}$ Medical Director, Exeter Hospiscare, The Exeter and District Hospice, Dryden Road, Exeter, UK \\ ${ }^{7}$ Macmillan General Practice Facilitator, Department of Primary Care, Peninsula College of Medicine and Dentistry, \\ St Luke's Campus, University of Exeter, Exeter, UK \\ ${ }^{8}$ Professor of General Practice and Primary Care, Department of Primary Care, Peninsula College of Medicine and \\ Dentistry, St Luke's Campus, University of Exeter, Exeter, UK
}

\begin{abstract}
Aim: To explore the experiences of people with advanced cancer and/or their caregivers accessing out-of-hours care. Background: The organisation and delivery of outof-hours in the United Kingdom has undergone major reforms over the past three decades culminating in the new General Medical Service contract in 2004. There are concerns around continuity of care for patients with complex needs under the new arrangements. Design: A qualitative interview study was undertaken recruiting patients from two primary care trusts in Southwest England. Semi-structured interviews were conducted with 28 people with advanced cancer and/or their caregivers who had recently requested out-of-hours care. Interviews were recorded, transcribed and analysed thematically. Findings: Two main themes were identified including the legitimacy of seeking help and continuities of care. Most participants were reluctant to seek help, finding it difficult to decide whether their needs were sufficient to contact services. The degree to which services legitimised participants' requests mediated their experiences. Distress arose when services were dismissive of their needs, whereas respondents were appreciative of clinicians who provided them with reassurance. Participants reported a lack of relational and informational continuity of care. Consulting with an unfamiliar clinician out-of-hours raised doubts in some participants' minds about the quality of care. Some participants recounted episodes in which there were problems with pain management. While the themes suggest that the delivery of out-of-hours care as a whole was not always perfect, around-the-clock access to professional sources of support and reassurance was highly valued. However, the transfer of information to out-of-hours providers remains a key challenge; participants did not understand why out-of-hours providers could not access more
\end{abstract}

\footnotetext{
Correspondence to: Dr Suzanne H. Richards, Department of Primary Care, Peninsula College of Medicine and Dentistry University of Exeter, Smeall Building, St Luke's Campus, Magdalen Road, EX1 2LU, UK. Email: suzanne.richards@ pms.ac.uk
}

C Cambridge University Press 2011 
information on their medical histories given the level of computerisation within the National Health Service. The findings highlight the need to improve continuity between in-hours and out-of-hours services for patients with complex needs.

Key words: accessing health care; cancer care; out-of-hours medical care; primary health care; qualitative study

Received 6 July 2010; accepted 1 November 2010; first published online 1 February 2011

\section{Introduction}

Reducing variation in access to cancer and palliative care services by improving patient and caregiver choice in the provision, location and timeliness of services, and in the equity of provision across different patient groups, is the key goal for UK National Health Service (NHS) development (Department of Health, 2000; House of Commons, 2003-04). Effective, around-theclock, co-ordinated care for people with advanced cancer and palliative care needs requires interagency working and communication (Thomas, 2000; 2003b; Gysels and Higginson, 2004).

Consistent with these aims, a major policy goal is to ensure the continuity of health care. 'Continuity' is a multi-dimensional concept, which has been defined in many different ways (Freeman et al., 2001), although three major components are consistently identified. Informational continuity is the use of information of past events and personal circumstances to make current health care appropriate for each patient. Relational (or 'personal') continuity relates to the ongoing therapeutic relationship between patient and clinician, which allows previous experiences to shape both the current and future care that are provided. Management continuity is defined as a consistent and coherent approach to the management of a health condition (including the actions of staff and the settings in which they operate) that is responsive to a patient's changing needs (Haggerty et al., 2003).

Out-of-hours primary care services have undergone major reorganisation over the past three decades in response to successive UK government policies (National Audit Office, 2006) culminating in the implementation of the new General Medical Services contract in 2004 (NHS Confederation \& British Medical Association, 2003).
Out-of-hours primary care services are now commissioned by local primary care organisations. As providers, out-of-hours services are operationally independent from daytime acute and primary care services. As such, out-of-hours staff do not have routine access to full NHS records (informational continuity), nor is it realistic to expect the clinical staff to have longstanding, personal relationships with the patients who contact the service (relational continuity). This has led to concerns with regard to the continuity of care for people with complex needs in the out-of-hours period, and particularly those with palliative care needs (Thomas, 2000; Murray et al., 2004; Worth et al., 2006). Recent health policy and guidance documents have highlighted the need to improve teamwork and inter-agency communication between out-of-hours primary care and daytime services (Department of Health 2006; Lakhani et al., 2007) to ensure that all aspects of continuity are addressed.

The general public calling out-of-hours have expressed concern about the urgency with which their cases are handled and the amount of time they have to wait for a call back or home visit (National Audit Office, 2006; Egbunike et al., 2008). A qualitative study (Richards et al., 2007) found that service users were often anxious about calling the service, in part due to concerns about whether their call was appropriate, combined with difficulties in conveying the nature and urgency of their problem. Once medical care is accessed, patients are generally complimentary about the health professionals' skills and the quality of care received (Richards et al., 2007; Egbunike et al., 2008). These findings mirror those of earlier studies reporting on the experiences of people with palliative care needs and their caregivers (King et al., 2004; Worth et al., 2006). However, given their advanced needs, 
relational continuity may assume particular importance, with the lack of access to familiar sources of professional help and support being felt keenly by patients and their families (King et al., 2004). Indeed, many such patients report that they prefer to wait to speak to their own doctor rather than calling an 'impersonal service' (Worth et al., 2006).

While studies have explored the experiences of people with palliative care needs seeking out-ofhours care in the United Kingdom, data collection took place before 2004 when the latest changes to out-of-hours primary care were implemented. This qualitative study therefore builds on existing work, by exploring the experiences and decision-making of people with advanced cancer and their caregivers when accessing out-of-hours care under the new arrangements.

\section{Methods}

The study was approved by the North and East Devon NHS Local Research Ethics Committee (05/Q2102/24) and the appropriate NHS trusts.

\section{Study design}

A qualitative study using semi-structured interviewing was conducted. People with advanced cancer and their caregivers were involved in the study design. Six hospice patients and caregivers gave feedback on the content of participant recruitment letters and information sheets. A user group, comprising 10 patients and caregivers attending a hospice day care unit, discussed their experiences of using out-of-hours services and helped inform the interview topic guide.

\section{Settings and sampling}

People with advanced cancer with palliative care needs and caregivers were sampled from two geographically and socio-economically diverse primary care trusts (PCTs, Plymouth and South Hams \& West Devon). At the time of data collection, although residents in each trust had access to broadly similar generalist and specialist services (Box 1), there were some notable exceptions. Twilight District Nursing was available only in Plymouth, and operational hours of treatment centres varied between trusts based on local demand. The Gold Standards Framework (GSF) for community palliative care (Thomas, 2003a) was being implemented in both areas.

Purposive sampling was used to maximise variation in age, gender and clinical histories, and the range of out-of-hours services accessed. Potential interviewees were deemed eligible if they met the inclusion criteria (Box 2).

\section{Participant recruitment}

Given the vulnerability of potential participants, the recruitment and data collection process required careful consideration (Lee, 1993). We involved clinical teams to minimise distress to potential participants, asking clinicians to approach only those individuals who might be sufficiently well enough to participate in a short interview within the next month. Participants were recruited through seven general practices, three community nursing teams, two acute hospital wards (haematology and oncology), two specialist palliative care nursing teams and a hospice. Recruitment continued until the data were analysed to be saturated. Clinical teams approached potentially eligible participants, providing them with written information about the study and a reply slip to return to the research team if the individual was interested in taking part. A researcher telephoned potential participants to answer any questions they might have and to arrange an interview as soon as possible after the reply slip was returned. Written consent was obtained from participants before the commencement of the interview.

\section{Data collection}

Each person was telephoned by the interviewer the day before the interview to ensure that they were well enough to participate in the interview. Given the advanced nature of participants' health problems, to minimise participant fatigue and burden, the interview was strictly limited to a maximum of $1 \mathrm{~h}$, and in most cases lasted no more than $40 \mathrm{~min}$. Within this context, a semi-structured interview approach was adopted to ensure that core topics of interest were covered. A topic checklist was developed through literature reviewing and user feedback, and used to guide the interview. Topics included peoples' awareness of the range of out-of-hours services available and 


\section{Box 1 Overview of clinical teams offering out-of-hours support}

\begin{tabular}{|c|c|c|c|}
\hline Team & Type of service & $\begin{array}{l}\text { Out-of-hours } \\
\text { availability }^{\mathrm{a}}\end{array}$ & $\begin{array}{l}\text { Clinically trained } \\
\text { staff }^{b}\end{array}$ \\
\hline NHS Direct & Telephone advice & Evenings and weekends & Registered nurses \\
\hline Ambulance Service & $\begin{array}{l}\text { Telephone advice } \\
\text { and home visit }\end{array}$ & Evenings and weekends & $\begin{array}{l}\text { Paramedics, } \\
\text { ambulance crew }\end{array}$ \\
\hline $\begin{array}{l}\text { Minor Injury Unit of } \\
\text { the Hospital }\end{array}$ & $\begin{array}{l}\text { Telephone advice } \\
\text { and treatment clinics }\end{array}$ & Evenings and weekends & Registered nurses \\
\hline $\begin{array}{l}\text { Oncology Ward of the } \\
\text { Hospital }\end{array}$ & Telephone advice & Evenings and weekends & $\begin{array}{l}\text { Registered nurses, } \\
\text { on-call doctors }\end{array}$ \\
\hline & Direct admission & Day-time on weekends & \\
\hline $\begin{array}{c}\text { Haematology Ward } \\
\text { of the Hospital }\end{array}$ & $\begin{array}{l}\text { Telephone advice } \\
\text { and direct admission }\end{array}$ & Evenings and weekends & $\begin{array}{l}\text { Registered nurses, } \\
\text { on-call doctors }\end{array}$ \\
\hline $\begin{array}{l}\text { Emergency } \\
\text { Department of the } \\
\text { Hospital }\end{array}$ & $\begin{array}{l}\text { Telephone advice } \\
\text { and direct admission }\end{array}$ & Evenings and weekends & $\begin{array}{l}\text { Registered nurses, } \\
\text { on-call doctors }\end{array}$ \\
\hline $\begin{array}{l}\text { Hospice Inpatient } \\
\text { Unit }\end{array}$ & Telephone advice & Evenings and weekends & $\begin{array}{l}\text { Registered nurses, } \\
\text { on-call doctors }\end{array}$ \\
\hline $\begin{array}{l}\text { Hospice Community } \\
\text { Nurse }\end{array}$ & $\begin{array}{l}\text { Telephone advice } \\
\text { and home visiting }\end{array}$ & Day-time on weekends & $\begin{array}{l}\text { Clinical nurse } \\
\text { specialists }\end{array}$ \\
\hline District Nursing & $\begin{array}{l}\text { Telephone advice } \\
\text { and home visiting }\end{array}$ & Day-time on weekends & Registered nurses \\
\hline $\begin{array}{l}\text { District Nursing } \\
\text { Twilight Service }\end{array}$ & Telephone advice & Evenings all week & Registered nurses \\
\hline $\begin{array}{l}\text { Out-of-hours Primary } \\
\text { Care }\end{array}$ & $\begin{array}{l}\text { Telephone advice, } \\
\text { treatment centres } \\
\text { and mobile units }\end{array}$ & Evenings and weekends & $\begin{array}{l}\text { General practitioners, } \\
\text { nurse practitioners }\end{array}$ \\
\hline
\end{tabular}

their reasons for, and experiences of, using these services when requesting help for urgent, unplanned health needs. The interviews were conducted by two researchers. The sociodemographic characteristics and living circumstances of participants were noted.

\section{Data analysis}

The interviews were audiotaped and transcribed verbatim. The data were anonymised (using fictitious initials) and analysed using the method of constant comparison (Strauss and Corbin, 1998). Three transcripts arising from early interviews were analysed by two independent researchers in order to develop provisional categories against which data could be indexed. The emergent themes were identified based on similarities of experience and then organised into a smaller number of overarching categories. Discrepant data and negative cases were sought to check the robustness of the emergent themes. The thematic analysis of data also ran alongside recruitment. Consequently, the coding of later interviews was informed by earlier ones, so that emerging issues could be explored. Summaries of each case were written describing the services used and the main themes emerging from their account 


\section{Box 2 Inclusion criteria for patients and caregivers of patients}

1. Participants were eligible if they:

- Had advanced cancer (ie, were receiving palliative treatment for a malignancy) or were a caregiver for such a patient

- Were aged $\geq 18$ years

- Had accessed an out-of-hours health-care service within the past year

- Were capable of at least $30 \mathrm{~min}$ of interview

- Were able to give consent to the study

2. Patients/caregivers were excluded if they had:

- A severe communication difficulty, which might limit their ability to participate

- Dementia or severe learning difficulties

3. Caregivers were eligible if they:

- Lived with or were in regular contact with the patient

- Were not paid professional caregivers

- For caregivers who were bereaved, the patient had died not less than three months ago or more than 12 months ago

in relation to an individual's repeated experiences of accessing out-of-hours care. These summaries avoided the fragmentation of peoples' accounts by maintaining the relationship between their views and their use of services, and have been used in similar settings (King et al., 2004). As a means of checking the reliability of the analysis, the themes and categories from the summaries were compared with those from the original coding of the transcripts, revealing a high level of congruence.

\section{Results}

\section{Sample}

Patients and caregivers were recruited between January and June 2006. Thirty-six patients and caregivers were approached and 23 (64\%) agreed to participate. Between agreeing to participate and the interview taking place two patients died and one became too unwell to participate. Thus, 20 interviews were conducted with 28 people (13 patients and 15 caregivers). The sociodemographic characteristics and living circumstances of participants varied considerably (Table 1), with the exception of ethnicity (all participants were White British).

\section{Study findings}

Over half the calls to out-of-hours services, for which a reason was given, were due to pain management (Table 2). Our participants had contacted out-of-hours services many times (Table 3 ), and by far the most commonly accessed service was outof-hours primary medical care; consequently, most peoples' comments relate to this service.

Two overarching categories were identified relating to the legitimacy of seeking help and continuities of care.

\section{Legitimacy of seeking help}

This category reflected the feelings of vulnerability experienced by participants after their doctor's surgery had closed, and their doubts about whether their condition was serious enough to merit a call. In all, 12 out of the 16 participants who discussed this theme reported delay in seeking help. The decision to call the service was seriously considered, as interviewees did not want to 'bother' anyone.

... night times it's ten times worse, you know. (...) you are very vulnerable, you know. You don't want to phone the doctor just to chat, that's for sure ....

(Mr LM)

Well I think you would find that almost anybody sat here, if it's a night time call, it's the uncertainty they feel in themselves, because I mean, you don't want to be upsetting anybody on their weekend if you don't have to, but if you are sitting there in pain and it's gone on several hours, you feel as if you have got to ring somebody, to do something about it just in case it does go on the whole weekend.

(Mr TA)

It is possible that people who live alone delay longer than others, possibly because there is no one to confirm the legitimacy of their needs. Where the person did not live alone, it was often the caregiver who finally took control and made the call, or encouraged the patient to do so. 


\begin{tabular}{|c|c|c|c|c|c|c|c|}
\hline Interviewee ${ }^{a}$ & $\begin{array}{l}\text { Patient's age } \\
\text { (years) }\end{array}$ & $\begin{array}{l}\text { Patient's } \\
\text { gender }\end{array}$ & $\begin{array}{l}\text { Patient lived } \\
\text { alone? }\end{array}$ & Caregiver identified & $\begin{array}{l}\text { Caregiver's } \\
\text { age (years) }\end{array}$ & $\begin{array}{l}\text { Caregiver's } \\
\text { gender }\end{array}$ & $\begin{array}{l}\text { Caregiver's } \\
\text { relationship }\end{array}$ \\
\hline Mrs AS & 70 & Female & Yes & No & - & - & - \\
\hline Mr and Mrs BL & 69 & Male & No & Yes, interviewed & 66 & Female & Spouse \\
\hline $\mathrm{Mr}$ and $\mathrm{Mrs} \mathrm{CT}$ & 51 & Female & No & Yes, interviewed & 52 & Male & Spouse \\
\hline Mr and Mrs DF & 61 & Female & No & Yes, interviewed & 60 & Male & Spouse \\
\hline Mr and Mrs EM & 61 & Female & No & Yes, interviewed & 61 & Male & Spouse \\
\hline Mr FP & Deceased & - & No & Yes, interviewed & 68 & Male & Spouse \\
\hline Mr GS & 76 & Male & Yes & Yes, not interviewed & - & - & - \\
\hline Mrs HT & Not interviewed & - & No & Yes, interviewed & 43 & Female & Daughter \\
\hline Mrs IB & Deceased & - & Not reported & Yes, interviewed & 51 & Female & Daughter-in-law \\
\hline Mr JK & Deceased & - & No & Yes, interviewed & 66 & Male & Spouse \\
\hline Mr KL & 96 & Male & Yes & No & - & - & - \\
\hline Mr LM & Deceased & - & No & Yes, interviewed & 68 & Male & Spouse \\
\hline Mrs MP & Not interviewed & - & No & Yes, interviewed & & Female & Spouse \\
\hline Mr and Mrs NS & & Female & No & Yes, interviewed & Not given & Male & Spouse \\
\hline Mrs OB & 77 & Female & Yes & No & - & - & - \\
\hline Mrs PD & Not interviewed & - & No & Yes, interviewed & 69 & Female & Spouse \\
\hline Mrs SB & 52 & Female & No & Yes, not interviewed & - & - & - \\
\hline Mr and Mrs TA & 71 & Male & No & Yes, interviewed & 68 & Female & Spouse \\
\hline Ms WA & 39 & Female & Yes & No & - & - & - \\
\hline $\begin{array}{l}\text { Mr RS and two } \\
\text { caregivers }\end{array}$ & 75 & Male & Yes & $\begin{array}{l}\text { Yes, two caregivers } \\
\text { present at interview }\end{array}$ & 66 and 67 & $\begin{array}{l}\text { Male and } \\
\text { Female }\end{array}$ & Friends \\
\hline
\end{tabular}

${ }^{a}$ All initials are fictitious. Interviews may be conducted with individual (patient or caregiver) or with pairs of respondents (eg, patient and their caregiver). 
Table 2 Reason for calling (were given)

\begin{tabular}{|c|c|c|c|c|c|}
\hline Initials $^{a}$ & Pain & Infection & $\begin{array}{l}\text { Chemotherapy } \\
\text { related }\end{array}$ & $\begin{array}{l}\text { Post-operative } \\
\text { complications }\end{array}$ & Miscellaneous $^{b}$ \\
\hline AS & 1 & & & & 2 \\
\hline $\mathrm{BL}$ & 1 & & & & 1 \\
\hline CT & $1+$ many & & & & 1 \\
\hline DF & 9 & 1 & & & 2 \\
\hline EM & 2 & & & & 1 \\
\hline $\mathrm{FP}$ & & 1 & 2 & & 1 \\
\hline GS & 1 & & & & 2 \\
\hline HT & & & 1 & & 4 \\
\hline IB & $1+$ few & & & & 2 \\
\hline $\mathrm{JK}$ & 3 & & & & \\
\hline $\mathrm{KL}$ & 1 & & & & 1 \\
\hline LM & $1+$ few & & & & \\
\hline MP & & 2 & & 2 & \\
\hline NS & 1 & & 1 & & \\
\hline OB & 5 & & & & 1 \\
\hline PD & & 2 & & & 1 \\
\hline RS & 2 & & & & 1 \\
\hline SB & & & & 2 & \\
\hline TA & 2 & & & & 1 \\
\hline WA & 2 & & & & \\
\hline Total & $>33$ & 6 & 4 & 4 & 21 \\
\hline
\end{tabular}

${ }^{a}$ Not everybody gave a reason each time they called the out-of-hours services.

${ }^{\mathrm{b}}$ This category includes less common reasons for calling the service. Examples include breathing difficulties (three instances), diarrhoea or constipation (two instances) and problems with prescriptions (two instances).

...my wife was dead against calling anybody. (...) Yes, she really was. 'Don't bother them with that', you know, and err, yeah, she didn't like me calling at all but I had to for my sake, you know.

(Mr LM)

There were six cases in which participants felt that the out-of-hours doctor had been dismissive of their concerns, thus denying the legitimacy of their calls. In all of these cases, the participants were very distressed by their experiences.

I felt, I felt a nuisance. You know, as if I had called him out and his time is far too precious to be dealing with us.

(Mrs HT)

...'Here am I, a GP administering an injection. Nurses can do that. You don't need a doctor to do this.' And I think the point perhaps he was really saying is that there may be some serious doctory things going on that he ought to be attending to, not applying - so I said to him, 'Well we don't have[nursing] cover'.

(Mr JK)

In the case of Mrs HT, she needed the doctor to acknowledge her fear that her father was dying, but this had not happened. Instead, she felt so affronted by his attitude that she said if he ever returned, 'I would not let him in'.

Although less common, there was one incident in which legitimacy was confirmed. Mrs AS had continued to experience pain following operations for breast cancer. She rang the out-of-hours service and the doctor who visited suspected the cancer had returned and arranged a hospital admission the following day. The cancer had returned and Mrs AS was impressed that her pain had at last been correctly diagnosed and was delighted with the out-of-hours doctor's manner.

While there were clearly specific instances recounted of problems accessing care from outof-hours primary care services, this should be balanced against the many positive accounts of using out-of-hours services. These accounts are

Primary Health Care Research \& Development 2011; 12: 165-178 


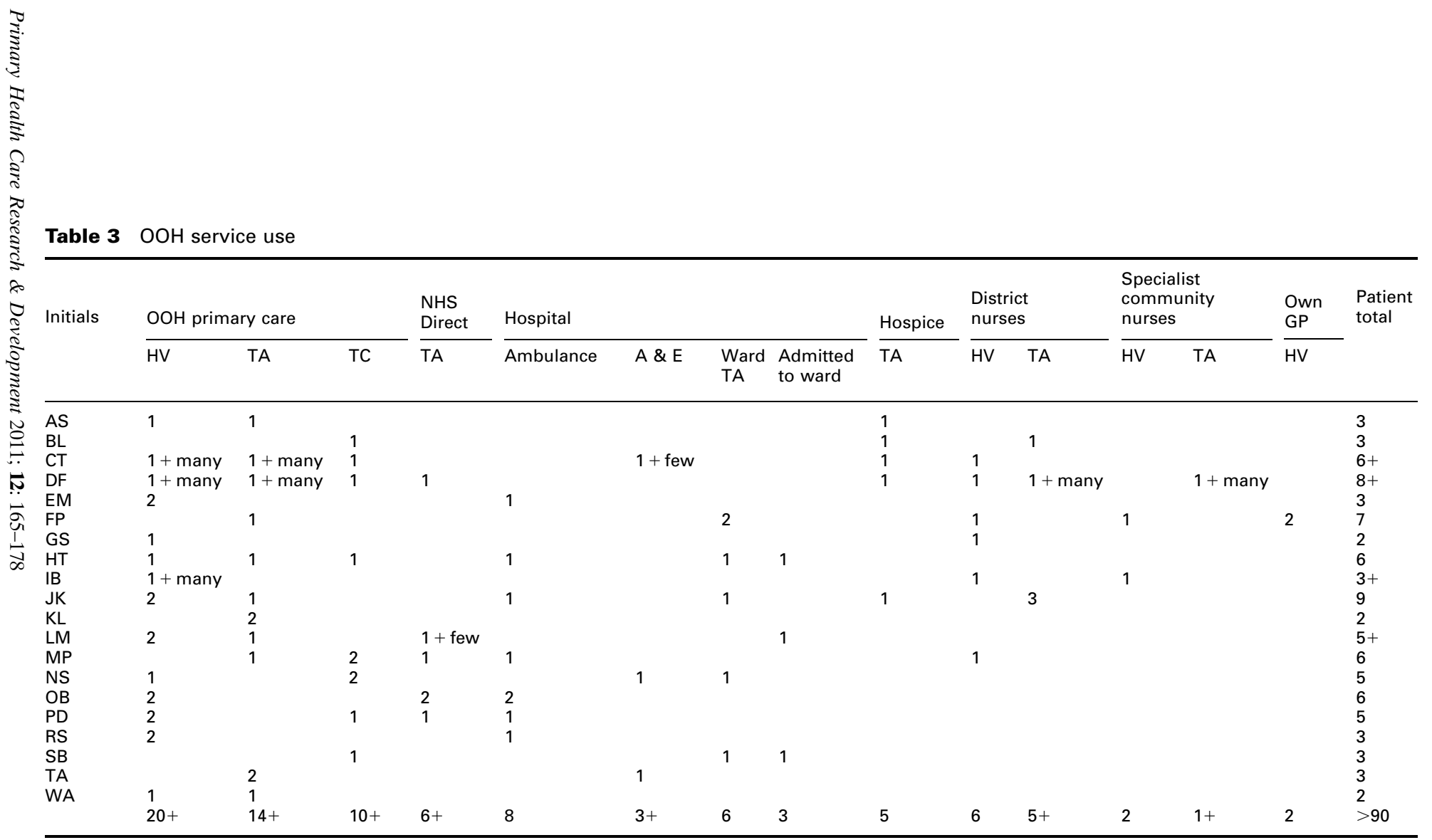

$\mathrm{OOH}=$ out-of-hours; NHS = National Health Service; GP = general practitioners; HV = home visit; TA = telephone advice; TC $=$ treatment centre visit; $A \& E=$ Accident \& Emergency department. 
much less detailed than stories of problematic encounters, and tended to be general reflections on the experience as a whole.

I was kind of dreading it and I did think to myself, oh no, I am ringing on a Sunday, I don't know what's going to happen, am I going to have to wait around for hours? And it wasn't the case, it was very, I was really pleased with them, with the treatment.

(Mrs SB)

I think what we'll say was that our whole experience was a good one and that erm, if we needed to use it then we were very confident about it.

$(\mathrm{Mr} F \mathrm{~F})$

There's nothing worse than feeling that you are on your own and there's no support and like it's the unknown. When you know that you can pick up the phone and at the other end are experienced professionals and they are like tuned in and that in a matter of minutes you can have assistance. That makes all the difference.

(Mr EM)

\section{Continuities of care}

While theoretical models clearly identify three components with regard to the continuity of care, in participants' accounts the different aspects (informational, management and relational) were interwoven. Difficulties in accessing help out-ofhours were experienced because familiar sources of professional support were unavailable (relational continuity), and the process of making an out-of-hours call was seen as lengthy and complicated due to a lack of informational and management continuity.

I would have loved to have picked up the phone and say to my health centre, 'Look Doc, [wife's name]'s got this problem again.' and he would have known. (...) And then we had to fill this form in and, over the telephone. 'Who is the patient, where do you live, what's the concern?' erm and maybe some other details as well, I can't remember clearly, but it was always the same, 'Who is your doctor, what's your health centre?' You know, blah blah and 'OK, a doctor will contact you'. And I remember thinking, I'm vulnerable, my wife is in pain and we want a service and, and I have to ring up this person - 'The doctor will contact you'! What, tonight? Tomorrow?

(Mr JK)

I think it was just the thought that, how do we do this? It seemed a long way round like, you know. (...) I think it was all the explaining that you would have to do. You didn't have anybody that you could ring up and say, erm, 'I am ringing up for (husband's name)' and they said, 'Ah yes'.

(Mrs TA)

People calling more than once in an evening or several times in quick succession were puzzled as to why they had to repeat the same information.

But each time you have to repeat exactly what has been (said) the week before. It's as though they haven't got the records there, they've got no visibility of what's gone on beforehand, you've got to tell a new story each time.

(Mr CT)

Concern that out-of-hours primary care services are unable to access patients' full, 'in-hours' medical records held in either primary or secondary care services was raised in 12 interviews. Several participants were concerned that the outof-hours doctors were 'at the mercy of the patient, how accurate they are' (Mr EM), which, in turn, raised safety issues with regard to medications and the ability to relate their often complex medical histories.

I know the first thing the doctor will ask you over the phone at [GP out-of-hours service] or indeed when the doctor calls, is, 'What medication is she currently on?' But logistics or logic states that the more likely a person is to be long term poorly, more likely they are to be older, more likely they are to be not quite as sharp as they were when they were younger and more prone to forgetting things.

(Mr EM)

While ideally participants desired relational continuity, that is, the ability to consult with a clinician 
who knew them and their medical history, most understood that this was unlikely to occur. Acknowledging this, most participants expected the clinician to be able to access a summary of their complex medical history. This could only be achieved by a combination of managerial and informational continuity. Several interviewees could not understand why, given the availability of computer technology, the out-of-hours services were unable to access their medical history.

I mean our own GP obviously knows Dad's case inside out, but there must be a way where the [out-of-hours] doctor can access at least a recapped version of what's wrong with him ... you would think he had to tap into his computer and access everything but, you know, he went solely on what I told him when we went in. So that to me was strange.

(Mrs HT)

I mean with everything being computerised now I would have thought that if I, if I phone up [GP out-of-hours service] then the person on the other end of the line should be able to go tap, tap, tap, whoof and everything is there.

(Mr DF)

On the other hand, $\mathrm{Mr}$ TA felt that it was unrealistic to expect out-of-hours doctors to be able to access the medical history of everyone who called. However, his point was that this made it all the more important for out-of-hours doctors to show the interpersonal skills necessary to understand their patients' needs and to provide much needed reassurance.

Well I don't see how they can ever cover, having everybody's information who happens to phone up that particular night can they? So I mean that's got to be too difficult. What you really want them to do, is to show some sort of understanding and try to give you some advice and help... least you feel as if someone has now got your case in hand and you won't be left to wander the moors as it were.

(Mr TA)

When seeking out-of-hours care, the particular needs of people with cancer were discussed in
12 interviews, with most participants indicating that they valued seeing a doctor who had some expertise in cancer and/or palliative care, particularly when undergoing active treatment. Two people remarked that out-of-hours general practitioners (GPs) do not usually have the necessary expertise. Mr EM remarked, '(...) of course they can only generally, I guess, be GPs or like, not specialists in a particular field', whereas Mrs HT said, 'Very nice doctors but, they, I don't know, they're general.'

Perhaps because of this, several people preferred to seek out-of-hours help from the oncology ward, especially if they were having chemotherapy. While this approach would certainly ensure access to the relevant expertise, by adopting this strategy, patients are also maximising the relational and managerial continuity in their care.

$\mathrm{He}$ [the oncologist] knew what he was talking about and that immediately gives you reassurance. You know, that you knew that he was an oncology doctor and you thought, well yeah, he knows what, and you know I always got it wrote down what I take so I just passed it to him and he knew.

Erm, that's the only people I can think of that would know enough about the situation. (...) Just basically because it's the cancer ward and I found, you know, they were really, really good, you know, when I was going into the chemo and stuff like that.

(Ms WA)

Difficulties in accessing pain relief out-of-hours were discussed in six interviews. A key issue was the speed with which this could be arranged given the severity of pain experienced. In some accounts, individual services or clinicians failed to respond as rapidly as the patient or caregiver would have liked. For example, Mrs CT had to call the out-of-hours primary care service frequently at one stage because of pain. Waiting for the doctor to visit was distressing for both her and her husband:

You know you get to, because I am sort of at the side looking at the pain and I am the one sort of getting stressed from it, she's suffering the pain and I am stressing, and I am 
thinking do I get in the car? Do I create more pain? You know, it's all these sorts of things that go through your mind.

(Mr CT)

One participant described inadequate care planning upon discharge from hospital. Mrs NS had been given morphine to control her pain during a three-week hospital admission but was discharged with only paracetamol for pain relief. As she said, 'A few hours out, I was climbing the walls'.

Others described problems when more than one provider was involved in an episode of care, consistent with difficulties in both informational and managerial continuity. For example, Mrs DF had been 'screaming literally with the pain in my back' and 'banging my fists against the wall with the pain' so her husband called the out-of-hours doctor and was advised to give his wife another painkiller. After a couple of hours, the pain had returned and Mr DF called the out-of-hours doctor again. This time the doctor visited them at home and arranged for an ambulance. However, they waited $4.5 \mathrm{~h}$ for the ambulance to arrive. On ringing the ambulance headquarters Mr DF was told that the doctor had not stated that it was an emergency.

\section{Discussion}

\section{Summary of main findings}

Although a range of different sources of support was available, the most frequently used and commented upon service was that of out-of-hours primary care.

We found that participants often felt vulnerable at the time of making out-of-hours calls and many were reluctant to contact such services until they were sure that it was appropriate. The need for reassurance permeated participants' accounts. The degree to which the service legitimised the request for medical help was paramount in mediating participants' experiences of care, with distress resulting when the service challenged the appropriateness of their requests. The finding of reluctance of participants to call for help out-of-hours is consistent with research conducted before the most recent service reorganisation with patients with palliative needs and their caregivers (King et al., 2004; Worth et al., 2006) and other service users within the general population (Richards et al., 2007). Similar difficulties have been reported in a study of service users contacting the NHS Direct (Goode et al., 2004). Goode et al. (2004) argue that the UK health service promotes individual responsibility for health, with patients conceptualised as consumers and a discourse of citizenship used to encourage consumers not to over-exercise their rights by being 'greedy'. The spectre of being considered a 'time-waster' is very powerful and patients feel the need to justify visiting the doctor and to assess whether their demand is legitimate. Goode et al. (2004) noted that, 'only responsibility for others seemed to override reflexive considerations of "deservingness": an explicit sense of entitlement to health and welfare services surfaced when adults were trying to access care on behalf of partners, elderly parents or children' (p. 223). This is certainly mirrored in our findings, as our participants were much more confident and forthright about the legitimacy of calling for help on behalf of others than they were for themselves.

Continuity of care was also important to our respondents. While theoretical models clearly identify three components (informational, management and relational) of continuity, in our participant's accounts they were interwoven. Relational continuity in out-of-hours care is increasingly unlikely and it has been suggested by others that informational and management continuity supplemented by good communication may enhance the experiences of patients with palliative care needs (Worth et al., 2006). We found a lack of both relational and informational continuity was described in relation to out-ofhours primary care; doctors did not personally know the patient nor appeared to have access to their medical history. Mechanisms already exist to enhance informational continuity, such as the use of hand-over forms ('special messages') supporting the transfer of enhanced clinical data sent from the in-hours services to the out-of-hours team (Thomas, 2000). Special messages are one component of the GSF for community palliative care, which had been implemented to varying degrees in our sampling area at the time of data collection. Data from an audit study in a different area found that special messages have not been widely implemented (in only $13.1 \%$ of palliative care patients' records; Burt et al., 2004). Although we have no way to verify whether special messages 
had been generated for our interviewees, our data suggest that there is a widespread perception that out-of-hours services had insufficient information about them. Consistent with this, the Royal College of General Practitioners has recently called for the wider use of methods to ensure that urgent care providers are aware of patients with complex needs (Lakhani et al., 2007).

In the absence of relational and informational continuity, the quality of a clinician's consultation skills assumed vital significance in supporting the legitimacy of the request and providing reassurance. While many participants would have preferred to see a familiar doctor, this preference did not appear to be born out of sentimentality. The concern was more about the quality of their medical care as it could be difficult to accurately convey complex information. There are two underlying explanations about informational continuity from a service perspective. The first is that the clinicians involved must take sufficient detail about the patient to ensure that each episode is safely managed, although at times this can seem frustrating or repetitive to those seeking help. New developments in the out-of-hours computer systems now allow clinicians to more readily identify patients who have previously called and their records can be more easily linked. However, the comprehensive adoption of computerisation by British GPs may have led patients to expect similar levels of technology throughout the NHS. Currently, there is no integration of primary care, hospital and out-of-hours primary care records.

In terms of management continuity, several qualitative studies have asked patients, caregivers and professionals to identify the essential elements of generalist care for dying people (Curtis et al., 2001; Borgsteede et al., 2006). Important aspects identified include the accessibility, approachability and technical skills of the doctors, with doctors who are willing to listen and explain things to patients in an unhurried manner being particularly valued. Our participants reported some of these aspects, but were particularly appreciative of professionals who had some expertise in cancer and/or end-of-life care.

Pain and symptom management is core to good quality end-of-life care (Curtis et al., 2001; Borgsteede et al., 2006), and out-of-hours access to controlled drugs is a key challenge for general practice and nursing teams (Thomas, 2003a). This resonates with our findings as the most common reason cited by our participants for calling out-ofhours primary care was pain management. Furthermore, negative experiences of care often coincided with an episode of poorly controlled pain.

Our initial aim was to explore people's choices and experiences of using out-of-hours care since the implementation of the new GP contract. This qualitative study cannot answer whether people's experiences have changed as a consequence of the new arrangements. However, when comparing our findings with the existing literature (King et al., 2004; Worth et al., 2006), the apparent stability of some of the main themes (with regard to helpseeking and continuity) suggests that the new arrangements have made little impact. Even our newer findings, such as the ever-increasing expectations with regard to computer technology, have no plausible basis arising from the new contract.

\section{Strengths and limitations of the study}

Recruiting participants at the end of life is difficult and some selection bias is inevitable. Nevertheless, the proportion of those who were approached and who refused to participate was low (36\%) suggesting that our methods were appropriate and sensitive. Our sampling strategy resulted in participants with varied disease histories and sociodemographic characteristics. However, although consistent with the Devon population profile (98.7\% 'White' in 2001 census), the lack of ethnic diversity suggests that our findings may be less applicable to such communities.

Our two overarching categories, relating to the legitimacy of seeking help and continuities of care, emerged from the data after applying rigorous analytical methods. However, by necessity we used a semi-structured approach to interviewing due to the vulnerability of study participants and the need to limit the length of interviews. Thus, the two emergent categories may have arisen, in part, due to the structure imposed on the data collection by the topic guide, and the different themes that may have arisen had a less structured approach to data collection been possible.

Although the interviews raised distressing issues, people were keen to talk about their experiences. Recruitment took place in two PCTs, both of which use the same out-of-hours primary care provider, and therefore, some findings may 
be service-specific. However, with over $95 \%$ of UK providers using the same ADASTRA ${ }^{\circledR}$ computer system (2010) and with no linkage between their records and that of other NHS services, the concerns over informational continuity have much wider applicability.

Finally, while many of the themes are characterised by details of negative episodes, the casestudy approach identified that many participants also recounted positive experiences (although in much less detail) relating to other times they had contacted the same service. While the delivery of out-of-hours care may not always be perfect, it is clear that the knowledge and reassurance provided by access to professional sources of support around-the-clock was highly valued by our participants.

\section{Conclusions}

Patients with advanced cancer and their families need reassurance and support when accessing outof-hours care due to their concerns with regard to the legitimacy of their requests. Ensuring continuity of care for patients with complex needs remains challenging. The need to improve the transfer of information to out-of-hours providers is a key target for both in-hours and out-of-hours teams. However, given that mechanisms already exist to facilitate the transfer of information between teams, further research is urgently needed as to why they remain under-used.

\section{Acknowledgements}

This study was funded by Macmillan Cancer Support (Registered Charity No. 261017). We gratefully acknowledge the valuable contribution of the study participants and their families who made this study possible and the clinical teams for helping with recruitment. We also thank Dr Sarah Human and Dr Pandora Pound for their contributions, feedback and support for this project.

\section{References}

Adastra. Website. Retrieved 3 June 2010 from www.adastra.com Borgsteede, S.D., Graafland-Riedstra, C., Deliens, L., Francke, A.L., van Eijk, J.T. and Willems, D.L. 2006: Good end-of-life care according to patients and their GPs. British Journal of General Practice 56, 20-26.

Burt, J., Barclay, S., Marshall, N., Shipman, C., Stimson, A. and Young, J. 2004: Continuity within primary care palliative care: an audit of general practice out of hours co-operatives. Journal of Public Health Medicine 26, 275-76.

Curtis, J.R., Wenrich, M.D., Carline, J.D., Shannon, S.E., Ambrozy, D.M. and Ramsey, P.G. 2001: Understanding physicians' skills at providing end-of-life care perspectives of patients, families, and health care workers. Journal of General Internal Medicine 16, 41-49.

Department of Health. 2000: The NHS cancer plan. London, UK: Department of Health.

Department of Health. 2006: National quality requirements in the delivery of out-of-hours services. London, UK: Department of Health.

Egbunike, J., Shaw, C., Bale, S., Elwyn, G. and Edwards, A. 2008: Understanding patient experience of out-of-hours general practitioner services in South Wales: a qualitative study. Emergency Medicine Journal 25, 649-54.

Freeman, G., Shepperd, S., Robinson, I., Ehrich, K. and Richards, S. 2001: Continuity of care. London, UK: National Co-ordinating Centre for NHS Service Delivery and Organisation Research and Development.

Goode, J., Greatbatch, D., O'Caithain, A., Luff, D., Hanlon, G. and Strangleman, T. 2004: Risk and the responsible health consumer: the problematics of entitlement among callers to NHS Direct. Critical Social Policy 24, 210-32.

Gysels, M. and Higginson, I. 2004: Improving supportive and palliative care for adults with cancer. Research evidence. London, UK: National Institute for Clinical Excellence.

Haggerty, J.L., Reid, R.J., Freeman, G., Starfield, B.H., Adair, C.E. and McKendry, R. 2003: Continuity of care: a multidisciplinary review. British Medical Journal 327, 1219-21.

House of Commons Select Committee on Health. 2003-04: Fourth Report of Session 2003-04: Palliative Care. HC 454-1. London: HM Government.

King, N., Bell, D. and Thomas, K. 2004: Family carers' experiences of out-of-hours community palliative care: a qualitative study. International Journal of Palliative Care Nursing 10, 76-83.

Lakhani, M., Fernandes, A., and Archard, G. 2007: Urgent Care. A position statement from the Royal College of General Practitioners March 2007. London, UK: RCGP.

Lee, R. 1993: Doing research on sensitive topics. London, UK: Sage.

Murray, S., Boyd, K., Sheikh, A., Thomas, K. and Higginson, I. 2004: Developing primary palliative care. British Medical Journal 329, 1056-57.

National Audit Office. 2006: The provision of out-of-hours care in England. London, UK: The Stationery Office.

NHS Confederation \& British Medical Association. 2003: The new general medical services contract. London, UK: The NHS Confederation.

Richards, S., Pound, P., Dickens, A., Greco, M. and Campbell, J. 2007: Exploring users' experiences of accessing out-of-hours 
178 Suzanne H. Richards et al.

primary medical care services. Quality and Safety in Health Care 16, 469-77.

Strauss, A. and Corbin, J. 1998: Basics of qualitative research. Thousand Oaks, CA: Sage.

Thomas, K. 2000: Out-of-hours palliative care - bridging the gap. European Journal of Palliative Medicine 7, 22-25.

Thomas, K. 2003a: The gold standards framework. London, UK: Macmillan Cancer Relief.
Thomas, K. 2003b: The Gold Standards Framework in community palliative care. European Journal of Palliative Care 10, 113-15.

Worth, A., Boyd, K., Kendall, M., Heaney, D., Macleod, U., Cormie, P., Hockley, J. and Murray, S. 2006: Out-of-hours palliative care: a qualitative study of cancer patients, carers and professionals. British Journal of General Practice 56, 6-13. 